\title{
Control-oriented modeling of diesel oxidation catalyst
}

\author{
Ying Gao*, and Hongqi Liu
}

State Key Laboratory of Automotive Simulation and Control, Jilin University, Changchun 130025, China

Keywords: diesel oxidation catalyst, temperature, modeling, thermal.

\begin{abstract}
Diesel oxidation catalyst outlet temperature control is crucial for heat management to realize diesel particulate filter active regenerative control. In order to control the temperature of the active regeneration process in the filter, the temperature response process of the semi-physical oxidation catalyst model structure is proposed as a multi-stage inertia plus delay, and the equivalent inlet temperature step of the fuel oxidation reaction of the exhaust pipe. Combined with the test test, the control oriented oxidation catalyst model is established.A control-oriented oxidation catalyst model was constructed. By analysed the oxidation catalyst working process, the main chemical reactions, heat and mass transfer processes occurring inside the carrier were analyzed. Three-dimensional CFD model and one-dimensional chemical reaction kinetics model were established respectively. The radial and axial temperature distribution of the carrier was analyzed by model simulation. Based on the analysis of the system characteristics, the multi-step inertia plus delay semi-physical model structure was proposed. Combined with the test, the control oriented oxidation catalyst model is established. Select the appropriate working conditions to identify and verify the model parameters. The results show that the third order model can well indicate the temperature response characteristics of the oxidation catalyst outlet temperature. Considering the complexity of the system, the first-order and third-order model are selected as the basis of the control system design.
\end{abstract}

\section{Introduction}

Because of the high thermal efficiency and strong power, diesel engines are widely used in heavy machineries and commercial vehicles. However, significant PM (particulate matter) and NOx from the diesel engine exhaust seriously damages environment. With the corresponding emission regulations increasingly tightening, the aftertreatment systems used to reduce PM and/or NOx is becoming an indispensable component in diesel engine systems, and numerous studies have been made in this field ${ }^{[1]}$.

\footnotetext{
*Corresponding author: jlliuhongqi@163.com
} 
DPF (diesel particulate filter) is a typical aftertreatment component in diesel engine system, which captures up to $90 \backslash \%$ of the PM in the exhaust ${ }^{[2]}$. However, the pressure drop of DPF will rise with the captured PM increasing, which may result the rise of exhaust back pressure. Hence, the captured PM needs to be regenerated and oxidized ${ }^{[3]}$. The PM regeneration includes passive regeneration and active regeneration. Passive regeneration oxidizes PM by NO2 in the exhaust; however, passive regeneration is slow, and is not able to fully satisfy the PM reduction requirement of most $\mathrm{DPF}^{[4]}$. Active regeneration quickly oxidizes PM by controlling the inlet temperature of DPF to a required range, generally $550-600^{\circ} \mathrm{C}{ }^{[5]}$. DOC (diesel oxidation catalysts) equipped upstream of DPF is always used to control the exhaust temperature to trigger the active regeneration of DPF ${ }^{[6]}$. The temperature rise is controlled by additional HC (Hydrocarbon) injection upstream of DOC. The injected HC oxidized in the DOC, and the released combustion heat rises the exhaust temperature. Because insufficient temperature rise cannot trigger the active regeneration, but immoderate temperature rise may damage the DPF, accurate temperature control of DOC is required ${ }^{[7-9]}$.

The modeling of DOC is a fundamental of the design and control of DOC systems. Multiple physical phenomena (mass, heat transfer etc.) and chemical reactions take place simultaneously in the DOC ${ }^{[10-11]}$. Because DOC is a distributed parameter system ${ }^{[12]}$, the mathematical form of its dynamic processes are all nonlinear partial differential equations, hence cannot be analytically solved. Considering the tradeoff between the modeling of axial direction characteristics and model simplicity, an improved control oriented DOC model is developed in this paper, Based on the 1-D physical model of DOC, a general varying parameter multi-order plus delay model is derived. Models of different orders are compared and experimental validated. In order to apply the proposed model in all operating conditions, simple data-driven models to estimate the varying parameters are also proposed and experimentally calibrated. Experimental results show that the proposed model is easy to be calibrated, and achieves high estimation accuracy with sufficiently low calculation effort for real-time control requirements.

\section{DOC modeling}

By analyzing the physical and chemical process of DOC system, the semi physical model structure based on physical characteristics is established, and the model parameters are identified with the test data, and the control oriented temperature response model of oxidation catalyst outlet is constructed.

\subsection{DOC thermal model}

After the engine exhaust gas passes through the carrier, the partial soluble organic matter (SOC, solid organic carbon) of $\mathrm{CO}, \mathrm{HC}$ and particulate matter will react with oxygen to convert into $\mathrm{CO} 2$ and $\mathrm{H} 2 \mathrm{O}$, which will emit certain heat. However, due to the limited pollutant composition in the exhaust gas, the temperature of the engine exhaust cannot be significantly increased. During the active regeneration of the particulate trap, the outlet temperature of the oxidation catalyst, i.e. CDPF inlet temperature, can be effectively increased by injecting diesel oil after the exhaust pipe to achieve the temperature conditions required for the active regeneration.

The physical and chemical reaction process of the oxidation catalyst is shown in Fig. 1, in which various diffusion, adsorption and oxidation-reduction reactions occur for different components in the exhaust gas in the channel. Platinum (PT), rhodium (RH), palladium (PD) and other precious metal catalysts are coated on the wall of the catalyst support channel, which can effectively reduce the reaction temperature of pollutants. 

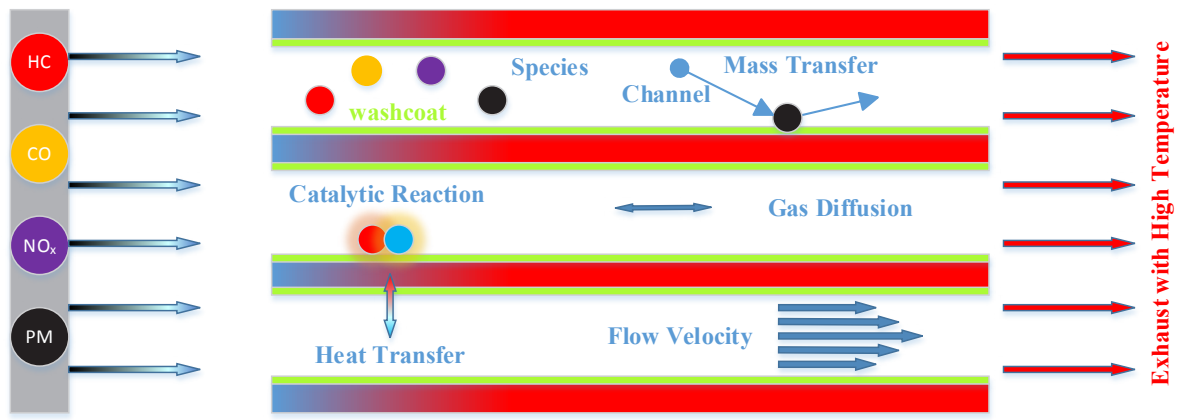

Fig. 1. Chemical reaction in DOC.

The components of pollutants in the exhaust gas will have chemical reactions in Doc, and the reactions are all reactions on the activation site of noble metal catalyst, which belong to gas-solid multiple catalytic reactions, and the main chemical reactions are ${ }^{[13-14]}$ :

$$
\begin{array}{r}
\mathrm{NO}+\mathrm{O}_{2} \rightarrow \mathrm{NO}_{2} \cdots \cdots \cdots \cdot . \\
\mathrm{CO}+\mathrm{O}_{2} \rightarrow \mathrm{CO}_{2} \cdots \cdots \cdots \cdots \\
\mathrm{H}_{x} \mathrm{C}_{y}+\left(\frac{x}{4}+y\right) \mathrm{O}_{2} \rightarrow y \mathrm{CO}_{2+} \frac{x}{2} \mathrm{H}_{2} \mathrm{O}
\end{array}
$$

In order to realize the active regeneration of DPF, the control of DOC outlet temperature mainly considers the heat release process of the system. However, with the chemical reaction of exhaust pollutants and diesel injected after the exhaust pipe in the oxidation catalyst, a large amount of heat will be released, and then the physical process of heat and mass transfer will occur, including the gas-solid heat transfer between the exhaust and the carrier, the heat transfer in the carrier and the heat transfer between the carrier and the environment Conduction. In addition, in the heat balance of the solid phase, there will be a chemical reaction between the substance in the exhaust gas component and oxygen to release heat. Therefore, a control oriented model of DOC outlet temperature is established.

\subsection{Modeling based on physical characteristics}

The response process of the outlet temperature of the oxidation catalyst belongs to the combination of delay and inertia. The reason is that the response time is needed for fluid transmission, and the heat transfer process of the system is inertia process. However, the modeling of the system needs to combine these two processes ${ }^{[15]}$, as shown in Figure 2. According to the characteristics of the system model, it is proposed that the temperature response process of the system is a multi order inertia plus delay model structure. The HC reaction heat release is equivalent to the step characteristic of the inlet temperature, because after the fuel enters the exhaust pipe, the reaction heat release is carried out in the oxidation catalyst, as shown in the $\mathrm{HC}$ reaction area in Figure 2. After passing through the reaction area, the inside of the carrier is completely a heat transfer process until the outlet of the carrier, and the process is equivalent to the process of transferring to the outlet of the carrier after the exhaust temperature at the front of the carrier rises. After equivalence, the model can keep the characteristics of multi order inertia plus delay. Then the temperature response process model of the system only has the time constant of inertia link and the time constant of delay link. But according to the different exhaust state of the engine, the response process of the system will be different. Therefore, each exhaust state can identify different parameters. 


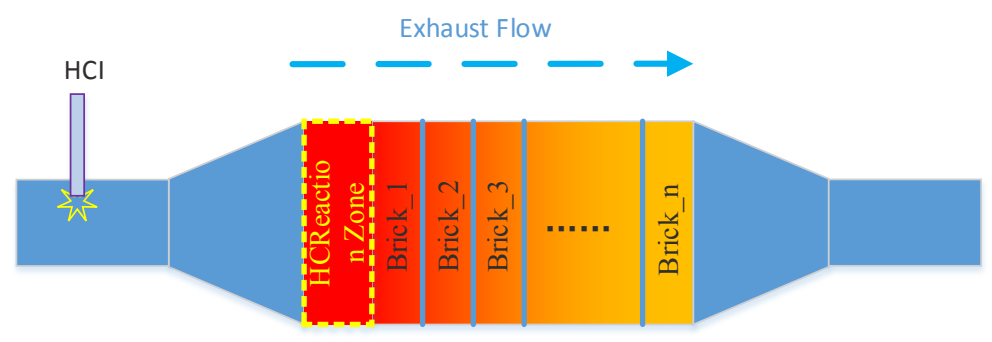

Fig. 2. Thermal Response Process In DOC.

If the carrier is uniformly divided into $\mathrm{n}$ elements, the thermal response model structure of the carrier is equation (1.4)

$$
\frac{T(z, s)}{T(0, s)} \approx \frac{k}{(\tau s+1)^{n}} \exp (-\delta s)
$$

Among them, is the response gain of the system, and the multi-order inertia response time constant and time delay of the system are variables related to the exhaust flow rate. Equation 1.4 is the transfer function of the proposed semi physical model. The model structure is determined, but the model order and parameter value cannot be determined. Combined with the experimental data, the nonlinear parameter identification method is used to obtain the numerical value of the model parameters, and the control oriented model of the oxidation catalyst is established. Because the time constant and time delay vary with the exhaust flow rate, it is necessary to analyze the nonlinear characteristics of the time constant and time delay in order to realize the adaptive parameters of the model.

\section{Model parameters identification}

\subsection{Model parameter identification and analysis}

Through the exhaust pipe fuel injection, the fuel injection quantity and the carrier inlet and outlet temperature data are measured respectively. As the basis of the oxidation catalyst model identification, combined with the equivalent inlet temperature step characteristics of fuel injection, the semi physical model parameters of the oxidation catalyst system are identified. Considering the time constant and time delay parameters of the system to be identified, it is necessary to select the operating conditions of different exhaust flow ranges to test the temperature response characteristics of DOC, and the selection of test conditions is shown in Figure 3. A total of 8 test condition points are selected, which can cover the exhaust flow range of the engine. At the same time, the change of the exhaust state of the model is carried out Feature verification: select the fast fluctuation between the high exhaust flow rate of $1127 \mathrm{~kg} / \mathrm{h}$ and the low exhaust flow rate of $444 \mathrm{~kg} / \mathrm{h}$ to judge the influence of the change process of exhaust state on the adaptability of the model.

The exhaust flow at the test condition point is shown in Figure 3. The minimum exhaust flow selected under the condition is $320 \mathrm{~kg} / \mathrm{h}$ and the maximum exhaust flow is $1384 \mathrm{~kg} / \mathrm{h}$, which can basically cover the engine exhaust flow range. 


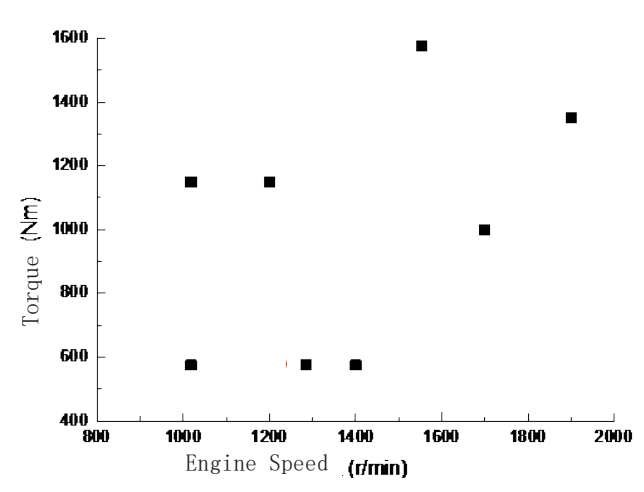

Fig. 3. Stationary operating points for identification.

Considering that there are obvious differences in the upstream temperature of DOC under different working conditions, and the value range of $\mathrm{HC}$ injection in the test is very large, it is difficult to directly compare the test data under different working conditions, so the test data measured under working conditions are normalized, and the normalization formula is set as follows:

$$
T_{\text {norm }}=\frac{T-T_{u s}(t)}{\max \left(T_{d s}\right)-T_{u s}(t)} \cdots
$$

The results of formula (2.1) can convert all the exhaust temperature data into $0-1$, i.e. the upstream exhaust temperature is 0 , and the downstream exhaust temperature is 1 . If it is a heating process, the temperature response shows a response characteristic of $0-1$. Otherwise, the response of the temperature drop process is $0-1$. In this case, the semi physical model parameter $\mathrm{k}=1$, which is converted into the pole form as follows:

$$
T_{\text {resp }} \approx \frac{p^{n}}{(s+p)^{n}} \exp (-\delta s) \cdots \cdots \cdots
$$

The model parameters are identified by the test data of 8 operating points. In the actual temperature response process, there is a change of temperature rise and fall. At each operating point, the process parameters of exhaust pipe fuel injection temperature rise and fuel shutdown temperature drop are identified respectively. At the same time, the temperature response process is normalized, so there is no k parameter in the output, and the system identification parameters are pole and delay parameters.

The comparison between model identification curve and test results of each operating point is shown in figure 4-11. The abscissa of rising process curve is $0 \mathrm{~s}$ to start the step injection of exhaust pipe fuel, and the abscissa of falling process curve is $0 \mathrm{~s}$ to start the stop injection of exhaust pipe fuel. It can be seen from the results that the model parameters are different under each working condition, including the delay time and model poles are not the same.

For the model parameter identification of each working condition, there is a certain error between the model identification results of different orders and the test results, and the magnitude of the error will reflect the accuracy of the model. In this paper, the model standard deviation is selected to evaluate the model parameter identification effect, and the calculation method of the standard deviation is equation 2.3:

$$
\sigma=\sqrt{\frac{1}{N} \sum_{i=1}^{N}\left(x_{i}-u_{i}\right)^{2}}
$$


The results show that with the increase of order, the standard deviation of fitting decreases gradually, and the accuracy of the model improves continuously. Considering the standard deviation of model identification and the complexity of the model, the first-order model and the third-order model are selected as the basic models of the control strategy design. The simplification of the model can provide convenient conditions for the design of the controller, and also simplify the design of the controller. The delay parameters of the first-order model vary from 13.427 seconds to 51.335 seconds, and the third-order model varies from 5.004 seconds to 34.570 seconds. The response delay of the system is large.

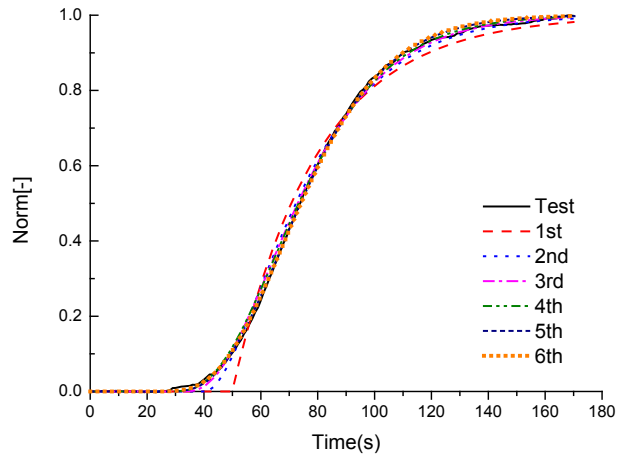

(a) Temp Rise Process

Fig. 4. Exhaust flow $=320 \mathrm{~kg} / \mathrm{h}$.

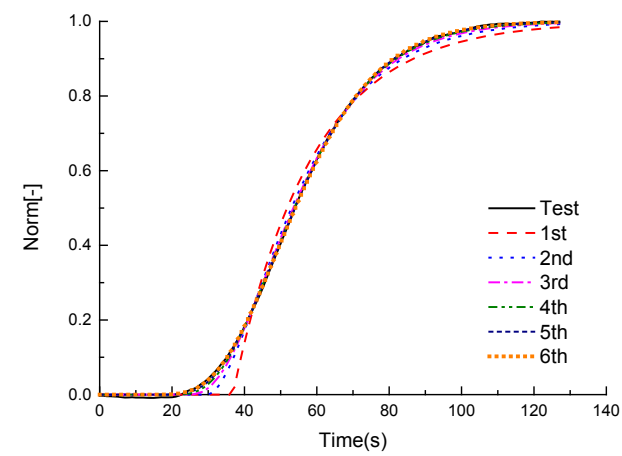

(a) Temp Rise Process

Fig. 5. Exhaust flow $=444 \mathrm{~kg} / \mathrm{h}$.

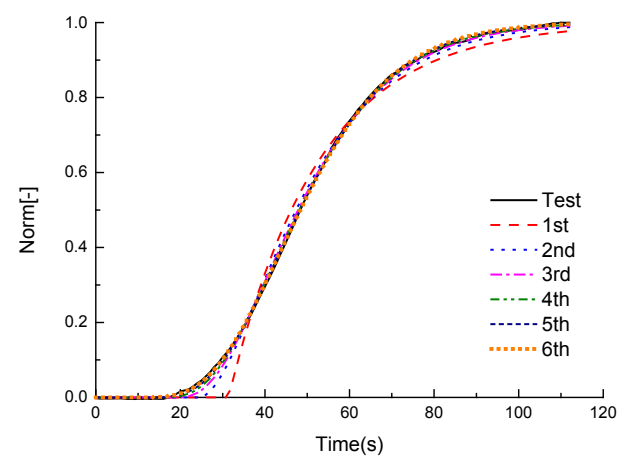

(a) Temp Rise Process

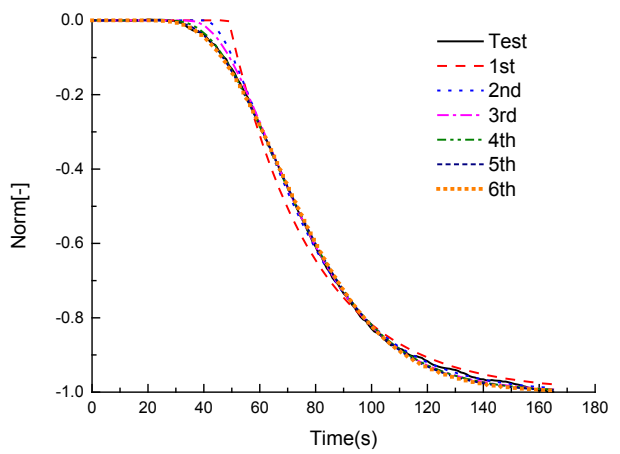

(b)Temp Down Process

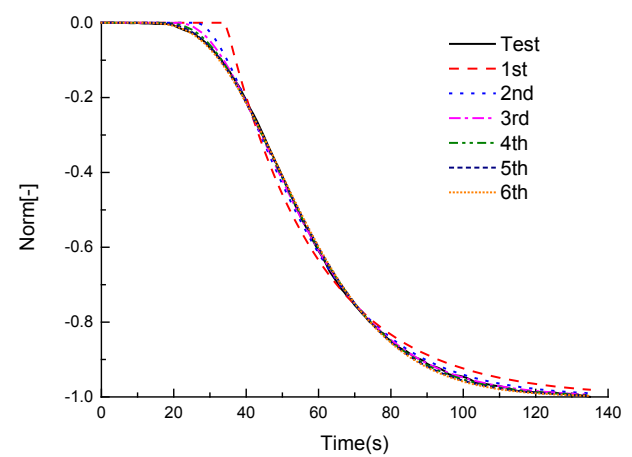

(b)Temp Down Process

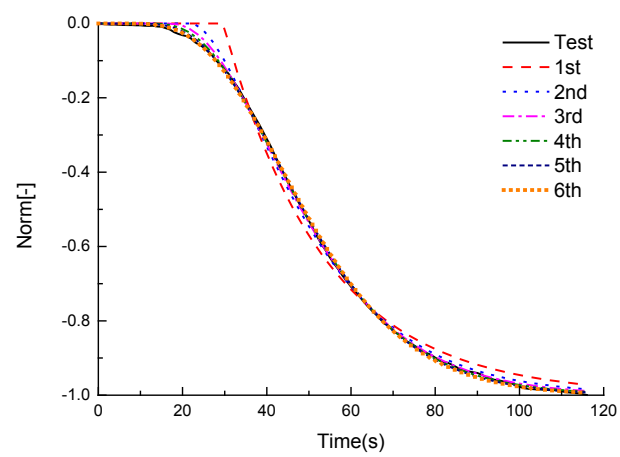

(b)Temp Down Process

Fig. 6. Exhaust flow $=495 \mathrm{~kg} / \mathrm{h}$. 


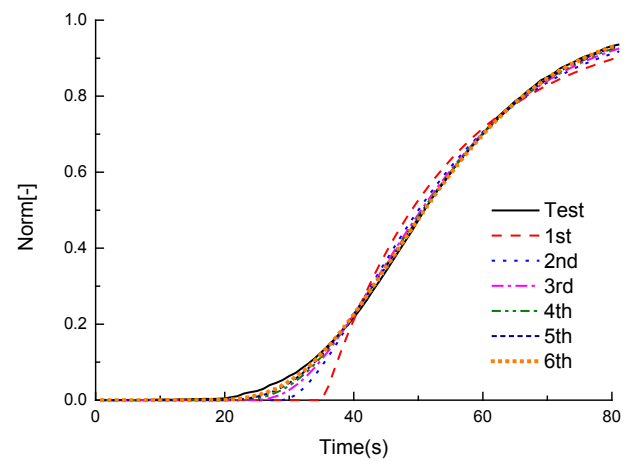

(b) Temp Rise Process

Fig. 7. Exhaust flow $=540 \mathrm{~kg} / \mathrm{h}$.

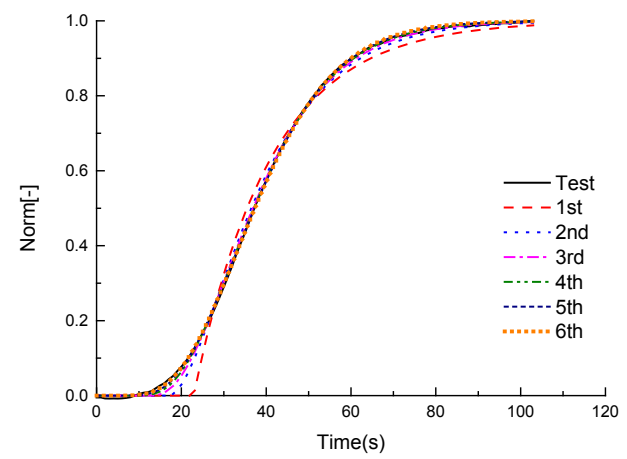

(a) Temp Rise Process

Fig. 8. Exhaust flow $=660 \mathrm{~kg} / \mathrm{h}$.

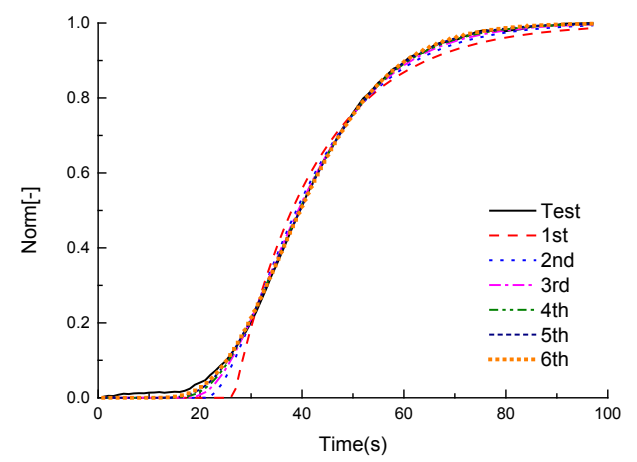

(a) Temp Rise Process

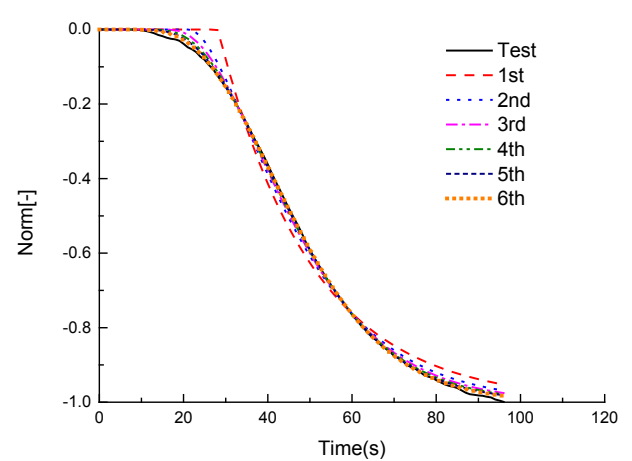

(b)Temp Down Process

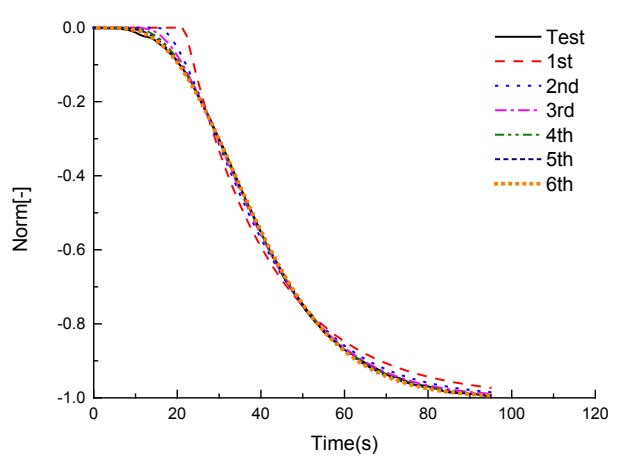

(b)Temp Down Process

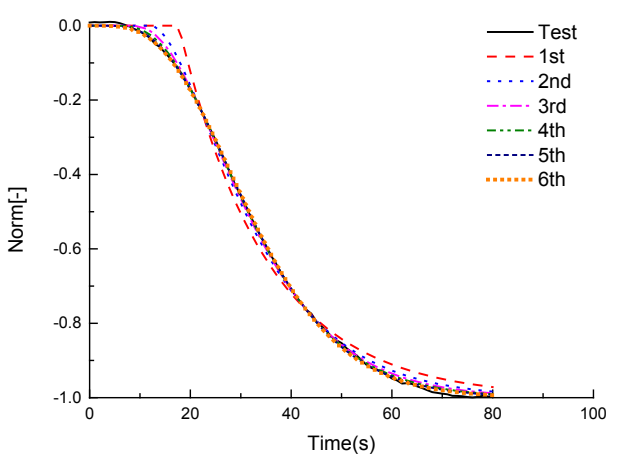

(b)Temp Down Process

Fig. 9. Exhaust flow $=950 \mathrm{~kg} / \mathrm{h}$. 


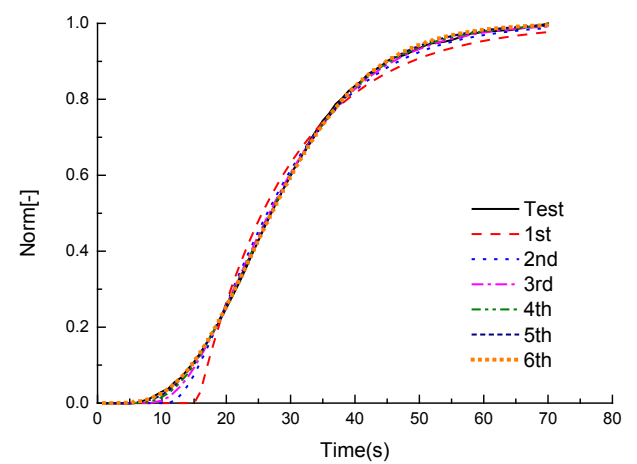

(a) Temp Rise Process

Fig. 10. Exhaust flow $=1100 \mathrm{~kg} / \mathrm{h}$.

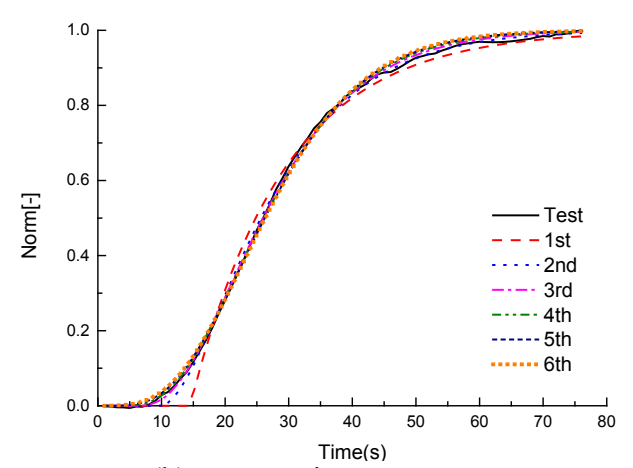

(b) Temp Rise Process

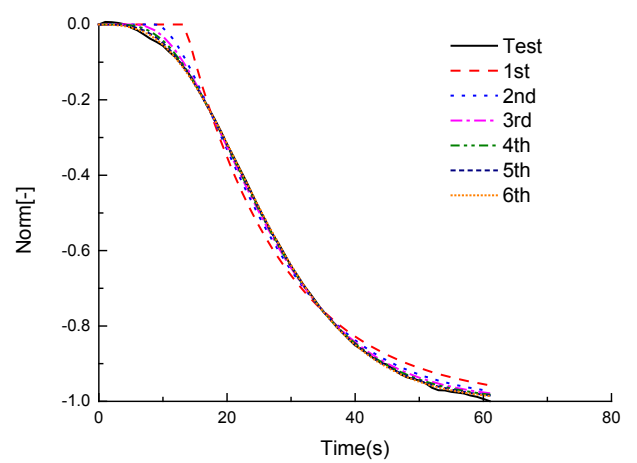

(b)Temp Down Process

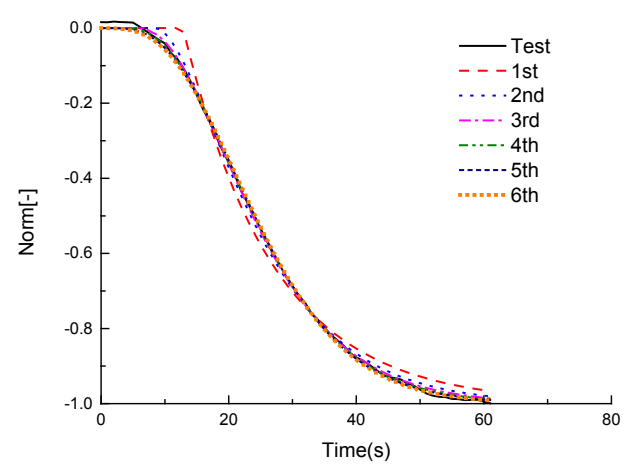

(b)Temp Down Process

Fig. 11. Exhaust flow $=1384 \mathrm{~kg} / \mathrm{h}$.

\subsection{Feature extraction of model parameters}

Through the identification of model parameters, it is found that a group of parameters can be obtained under each working condition, which is caused by the nonlinearity of the system. In this paper, the law of nonlinear change of the model is studied, and the parameter characteristics under different working conditions are modeled, which is transformed into the model parameters related to exhaust flow.

The fitting equations of the model poles and time delay parameters are equation 2.4/2.6 and equation $2.5 / 2.7$, in which pole $\mathrm{P}$ and exhaust flow show a linear relationship and the time delay parameters and exhaust flow show a hyperbolic function relationship. By using this fitting method, the efficiency and universality of the algorithm are further improved, that is to say, the variation law between parameters and exhaust flow is obtained.

Using the same method, the fitting results of parameter characteristics of the third-order plus delay model under different working conditions are obtained. The regular parameter equation of the third-order pole position and exhaust flow in the process of temperature rise:

$$
p(u)=7.061 \times 10^{-5} \times u+0.05697
$$

In the process of temperature rise, the law between the third-order delay parameter and exhaust flow is 


$$
T_{d}(u)=\frac{1.245 \times 10^{4}}{u}-4.916
$$

The regular parameter equation of the third-order pole position and exhaust flow in the process of temperature drop:

$$
p(u)=7.018 \times 10^{-5} \times u+0.0474
$$

The law between the third-order delay parameter and exhaust flow rate is

$$
T_{d}(u)=\frac{1.116 \times 10^{4}}{u}-5.412
$$

\subsection{Verification of exhaust state change model}

Because the model of temperature response at the outlet of oxidation catalyst is developed on the basis of the semi physical model established by analyzing the response characteristics of physical system. The model is based on the temperature from the inlet to the outlet and the fuel injection relationship. However, the exhaust state of the engine is in a changing process in the actual operation process, and the model has not considered the change of exhaust state, that is, the state switching process, so it is necessary to further verify the adaptability of the model to the change of exhaust state. The exhaust state with continuous change, including a process of exhaust flow decreasing and rising, is selected to study the difference between the calculated value of the model and the actual value. The selected continuously changing exhaust state is shown in Figure 12, with the maximum exhaust flow of $1127 \mathrm{~kg} / \mathrm{h}$ and the minimum exhaust flow of $444 \mathrm{~kg} / \mathrm{h}$.

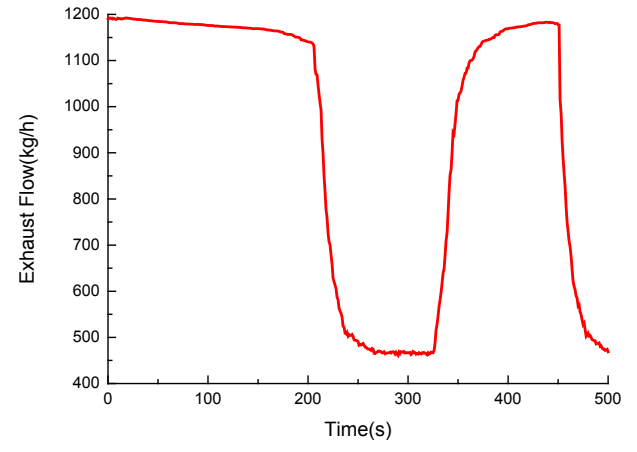

Fig. 12. Exhaust flow variation process.

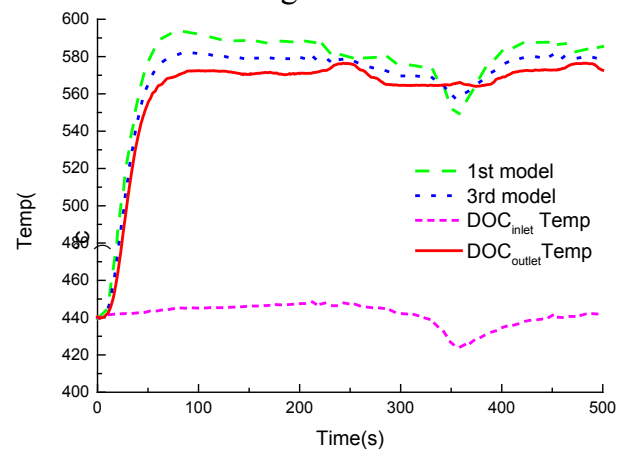

Fig. 13. Temp variation process.

In the process of engine exhaust flow changing greatly, the results of model calculation can effectively characterize the temperature response law of the oxidation catalyst outlet. The fluctuation range of the third-order model is about $\pm 10{ }^{\circ} \mathrm{C}$ in Figure 13 , so the high-order model also better reflects the temperature response characteristics of the oxidation catalyst.

In conclusion, the model based on physical characteristics can characterize the temperature change process of oxidation catalyst, and the model is simple, which can be used for control strategy development to ensure the real-time performance of the system. And through the analysis of the model parameters, the adaptive model of exhaust state change is constructed effectively. Through the comparative analysis of numerical simulation and experimental data, the accuracy of different order doc model is compared, and the rationality and complexity of parameters are analyzed. The third order inertial plus 
delay carrier temperature model is selected as the basic model of control strategy development.

\section{Conclusion}

The adaptive control algorithm based on the third-order model is verified by the transient process. In the transient mode, the outlet temperature of the oxidation catalyst can still be effectively controlled within $\pm 10{ }^{\circ} \mathrm{C}$ of the target temperature.

This paper is supported by a National key research and development plan development of energy conservation and environmental protection agricultural engine, and the project number is 2016YFD0700800.

\section{Reference}

1. Johnson, T. and Joshi, A., Review of Vehicle Engine Efficiency and Emissions. SAE Technical Paper 2018-01-0329,2018

2. Nakamura K, Vlachos N, Konstandopoulos A, et al. Performance improvement of diesel particulate filter by layer coating[C]. SAE Technical Paper 2012-01-0842,2012.

3. Konstandopoulos A G, Kostoglou M, Skkaperdas E, et al., Fundamental studies of desel particulate filters: transient loading, regeneration, and aging[C], SAE Technical Paper 2000-01-1016,2000.

4. Khair MK. A review of diesel particulate filter technologies. In: Future Transportation Technology Conference \& Exposition. SAE International; 2003-01-2303, 2003

5. Surenhalli H S, Premchand K, Johnson J H, et al. Modeling study of active regeneration of a catalyzed particulate filter using one-dimensional DOC and CPF models[R]. SAE Technical Paper, 2011.

6. Lepreux O, Creff Y, Petit N. Warm-up strategy for a diesel oxidation catalyst[C]//Control Conference (ECC), 2009 European. IEEE, 2009: 3821-3826.

7. Lepreux O. Model-based temperature design of a diesel oxidation catalyst [D].Paris: MINES ParisTech, 2009.

8. Song X, Surenahalli H, Naber J, et al. Experimental and modeling study of a diesel oxidation catalyst (DOC) under transient and CPF active regeneration conditions[R]. SAE Technical Paper, 2013.

9. Lepreux O, Creff Y, Petit N. Model-based temperature control of a diesel oxidation catalyst[J]. Journal of Process Control, 2012, 22(1): 41-50.

10. Koltsakis GC, Stamatelos AM. Modeling dynamic phenomena in 3-way catalytic converters. Chemical Engineering Science 1999;54(20):4567 -78.

11. Tang, T., Cao, D.X., Zhang, J., Zhao, Y.G., Shuai, S.J., 2014. Experimental Study of Catalyzed Diesel Particulate Filter with Exhaust Fuel Injection System for Heavy-duty Diesel Engines. SAE Technical Paper 2014-01-1496,2014.

12. Lepreux O, Creff Y, Petit N. Model-based control design of adiesel oxidation catalyst. IFAC Proceedings Volumes 2009;42(11):279 - 84.

13. Harned J. Analytical evaluation of a catalytic converter system[C]. SAE Technical Paper 720520, 1972 
14. H.Mohammed. The Filtration and Oxidation Characteristics of a Diesel Oxidation Catalyst and a Catalyzed Particulate Filter: Development of a 1-D 2- Layer Model[D]. MichiganTechnological University, 2005.

15. Ozisik M N. Inverse heat transfer: fundamentals and applications[M]. CRC Press, 2000. 